Utah State University

DigitalCommons@USU

\title{
Using Systematic Conservation Planning to Establish \\ Management Priorities for Freshwater Salmon Conservation, Matanuska-Susitna Basin, AK, USA
}

Andrew W. Witt

Utah State University

Edd Hammill

Utah State University

Follow this and additional works at: https://digitalcommons.usu.edu/eco_pubs

Part of the Aquaculture and Fisheries Commons

\section{Recommended Citation}

Witt A, Hammill E. Using systematic conservation planning to establish management priorities for freshwater salmon conservation, Matanuska-Susitna Basin, AK, USA. Aquatic Conserv: Mar Freshw Ecosyst. 2018;28:994-1003. https://doi.org/10.1002/aqc.2933

This Article is brought to you for free and open access by the Ecology Center at DigitalCommons@USU. It has been accepted for inclusion in Ecology Center Publications by an authorized administrator of DigitalCommons@USU.

For more information, please contact

digitalcommons@usu.edu.

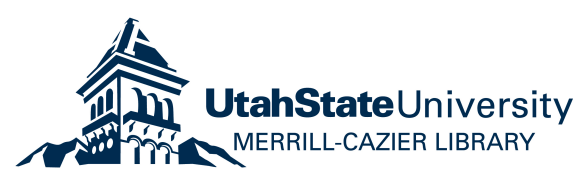



salmon conservation, Matanuska-Susitna Basin, AK, USA

Andy Witt ${ }^{1}$, Edd Hammill ${ }^{1}$

$4 \quad{ }^{1}$ Department of Watershed Sciences and the Ecology Center, Utah State University, Logan, UT, USA.

Author for Correspondence: Edd Hammill, Department of Watershed Sciences, Utah State

Email: edd.hammill@usu.edu

\section{Abstract:}

1- The Alaskan Matanuska-Susitna Basin (MSB) provides habitat for all five Pacific salmon species, and their large seasonal spawning runs are important both ecologically and economically. However, the encroachment of human development through urbanization and extractive industries poses a serious risk to salmon habitat in the MSB.

2- Using systematic conservation planning techniques, different methods of incorporating anthropogenic risks were assessed to determine how to cost-effectively conserve salmon habitat in the area.

3- The consequences of four distinct conservation scenarios were quantified: no consideration of either urbanization or extractive industries ('Risk ignored' scenario); accounting for the risk of urbanization, and avoiding conservation in all fossil fuel rich areas ('Urbanization accounted, all extraction avoided' scenario); accounting for urbanization and oil and gas development, but avoiding conservation in coal rich areas 
('Urbanization accounted, coal areas avoided' scenario); and accounting for all anthropogenic risks to habitat, and allowing conservation in oil, gas, or coal rich areas ('All risks accounted' scenario). To compare conservation success and resiliency, the impact of these risks were estimated using Monte Carlo simulations. The final cost of each solution was then divided by the number of conservation targets met to determine a return on investment.

4- Results from scenarios that avoided all extractive activities, or just coal, suggest that

Development conservation targets cannot be met by simply avoiding fossil fuel rich areas, and these scenarios resulted in lower returns on investment than when risks from extraction were incorporated into the solution.

5- By providing economically rooted conservation prioritization, this study provides a method for local managers and conservation groups to identify conservation opportunities in MSB river basins.

Keywords: River, Disturbance, Habitat Management, Landscape, Fish, Industry, Mining, Urban 


\section{Introduction:}

Quantifying and incorporating the uncertainty surrounding the potential success of management actions is crucial to making cost effective conservation decisions. A key source of uncertainty is the risk posed to natural ecosystems by anthropogenic activities, a factor that is critical to incorporate in order to give conservation actions the best chance of success (Bode et al., 2009, Tulloch et al., 2013). For landscapes threatened by events that negatively impact biodiversity, quantifying the spatial distribution of risk sources, and including them into conservation plans can increase the overall return on conservation investments (Hammill, Tulloch, Possingham, Strange, \& Wilson, 2016). In many parts of the world, landscapes with high biodiversity are threatened by encroaching housing development, as people seek to live near areas of natural beauty. In addition, growing populations increase the demand of natural resources such as oil, gas, and coal. For areas experiencing both population growth and increased pressure on local natural resources, quantitatively assessing where development should and should not take place is crucial to ensure the survival of local ecosystems and their species (Butt et al., 2013).

The Matanuska-Susitna Basin (MSB) covers over 25,000 square miles (approximately 64,750 square kilometres) of south-central Alaska. This basin provides habitat for all five Pacific salmon species (Supplementary material): Chinook salmon (Oncorhynchus tshawytscha), chum salmon (Oncorhynchus kisutch), coho salmon (Oncorhynchus keta), sockeye salmon (Oncorhynchus nerka), and pink salmon (Oncorhynchus gorbuscha). The ecological importance of salmon spans both aquatic and terrestrial ecosystems. Spawning salmon feed bears, wolves, eagles, and other streamside animals, and after completing their life cycle they provide carbon, nitrogen, and 
phosphorus to streams and surrounding riparian areas (Juday, Rich, Kemmerer, \& Mann, 1932; Shuman, 1950). These crucial nutrients can be distributed hundreds of kilometres inland from streams, even into upland forests (Reimchen, 2000). Estimates of sockeye salmon returns in Bristol Bay, Alaska, predict 20 million salmon during large years, producing over 54 million kilograms of biomass (Gende, Edwards, Willson, \& Wipfli, 2002). Their role as agents of nutrient transfer between marine, aquatic and terrestrial systems means that the lives of thousands of individual organisms depend on healthy salmon runs and the resources they provide (Willson, Gende, \& Marstron, 1998; Cederholm, Kunze, Murota, \& Sibatani, 1999).

Additionally, the chinook, coho, and sockeye salmon are of particular importance to commercial and recreational industries (Hughes, 2013). Commercial harvest from the Cook Inlet alone brought in more than $\$ 10$ million U.S. dollars in 2010 (Shields \& Dupuis, 2012). Recreational fishing provides additional revenue, having generated \$29 million dollars in 1986, and are estimated to have increased by $15 \%$ to $25 \%$ between 1986 and 2003 , a trend that is expected to continue (Sweet, Ivey, \& Rutz, 2003). However, both commercial and recreational revenues are dependent on seasonal spawning returns, which are influenced by the availability of suitable spawning habitat. Within the MSB, the availability of high quality, suitable spawning habitat is threatened by rapid urbanization and extraction of natural resources, both of which have the potential to seriously impact local salmon freshwater life stages (Stromberg \& Scholz, 2011; Alderman, Lin, Farrell, Kennedy, \& Gillis, 2016).

Anchorage, Alaska's largest city, resides at the confluence of the MSB drainage and the Cook Inlet to the Pacific Ocean. The proximity of this metropolitan region to the salmon-bearing tributaries of the MSB has increased the anthropogenic impairment of salmon habitat. As of 
2000, 42\% of all Alaskans lived within the Anchorage municipal boundaries (Municipality of Anchorage, 2001). Anchorage accounted for almost half of the state's population growth during the 1990s, and the area's rate of growth is faster than the majority of metropolitan areas in the United States (Municipality of Anchorage, 2001). Between 2001 and 2009, this trend continued; $41.3 \%$ of the state's growth occurred in Anchorage, and 34.1\% of the state's growth occurred in the MSB (Keith, Erben, \& Dapcevich, 2010). Together, the growth of Anchorage and the MSB accounted for $74.4 \%$ of the state's growth between 2001 and 2009. Development in the MSB has been 'out not up', with residential buildings sprawling beyond established communities, as many residents desire to make their homes adjacent to streams and lakes. An estimated 31\% of MSB residents commute to Anchorage. Due to the rural demand for housing, agricultural land is being converted for residential development and retail (Mat-Su Salmon Partnership, 2013).

With increasing urbanization in the MSB, several anthropogenic impacts on the environment have threatened salmon spawning habitat. Loss of wetlands and riparian habitat, reductions in water quality and quantity, all terrain vehicle (ATV) use within stream channels, and culvert installation, have all concerned the Alaska Department of Fish and Game (ADF\&G) as human caused impacts on salmon habitat (Hughes, 2013). Not only are urban land use changes responsible for habitat impairment, but also oil, gas, and mining operations jeopardize freshwater salmon habitat.

Rich, high quality mineral deposits remain an untapped resource for the MSB, with the greatest mining potential being rich coal deposits. Recent estimates from the Usibelli Corporation predict an annual yield of 500,000-700,000 tons (approximately 453,000- 635,000 metric tonnes) in coal 
111 production spanning twelve years (Metiva \& Hanson, 2008). As of September 2016, Alaska

112 Department of Natural Resources Division of Mining renewed Usibelli's mineral lease to this

113 coal deposit (Hollander, 2014), and two additional mine proposals target the same coal deposit.

114 As large mining operations remove mass from a drainage, groundwater flow paths, water quality,

115 sediment transport, and fish access to habitat all become altered (Mat-Su Salmon Partnership,

116 2013). In addition to mining coal, companies are pursuing coal-bed methane extraction. A 2007

117 pilot project by Fowler Oil and Gas Corporation started tapping the existing reserves (Metiva \&

118 Hanson, 2008). Installation of well pads, roads and pipelines can lead to habitat fragmentation

119 and sedimentation. Furthermore, accidental spills present unpredictable environmental risks associated with extractive resource development (Brittingham, Maloney, Farag, Harper, \&

121 Bowen, 2014). The presence of extractive industries in the landscape make necessary to quantify

122 how different attitudes towards risk affect the chances of conservation success. Specifically,

123 conservationists need to address whether effective conservation of salmon habitat can take place

124 by just avoiding areas where extractive industries are present.

126 To maximize conservation efforts in landscapes facing anthropogenic development, systematic

127 landscape planning software can be applied to provide cost effective, prioritized conservation

128 solutions to optimize conservation investments. Systematic landscape planning software

129 originally focused on conservation in terrestrial and marine ecosystems, however applications to

130 lotic ecosystems require additional modifications. By applying existing terrestrial and marine

131 procedures, protected areas may be clustered across catchment boundaries, not defined by stream

132 networks. Failing to include the flowing nature of lotic ecosystems means that the solutions

133 generated do not account for the connective habitat requirement of some riverine species, 
134 especially species with large ranges (Fausch, Torgersen, Baxter, \& Li, 2002). Fortunately,

135 several authors have clarified topological rules to better represent the connectivity between

136 upstream and downstream habitats, increasing systematic conservation planning applications to

137 lotic ecosystems (Hermoso, Linke, Prenda, \& Possingham, 2011; Esselman \& Allan, 2011;

138 Linke et al., 2012).

139

140 Using systematic conservation planning techniques, a series of scenarios were developed to

141 determine management priorities for salmon spawning habitat conservation, including how

142 spawning habitat is impacted by urbanization, oil and gas, and coal development. Four distinct

143 scenarios were developed to test how different risk sources influence spawning habitat

144 conservation priorities:

145

146

147

148

149

150

151

152

153

154 Naidoo et al. (2006) established that incorporating economics into conservation plans yield 155 156

- Ignoring all anthropogenic risks to habitat, both urbanization and fossil fuel extraction ('Risk ignored')

- Accounting for risk associated with urbanization, avoiding all areas with fossil fuel extraction and deposits ('Urbanization accounted, all extraction avoided')

- Accounting for risk associated with urbanization, avoiding all areas with coal extraction and deposits ('Urbanization accounted, coal areas avoided')

- Accounting for risks associated with both urbanization and fossil fuel extraction, all areas are however available for conservation ('All risks accounted') greater biological gains over plans ignoring costs. Therefore, land use data were used to calculate opportunity costs (in terms of lost potential revenue) of designating areas for conservation. These 
157 land costs were then combined with data on spawning habitat locations to ultimately identify

158 areas that represent conservation priorities under each scenario.

159

160

\section{Methods:}

161

162 Conservation Planning Overview

163 Marxan with probability optimization software was used in conjunction with environmental risk

164 surface (ERS) models to identify priority salmon spawning habitat. (Fig. 1). Marxan software

165 offers conservation planners decision support by optimizing which areas should be set aside for

166 conservation to achieve a desired conservation goal (Possingham, Wilson, Andelman, \& Vynne,

167 2006; Moilanen, Wilson, \& Possingham, 2009). Within a Marxan analysis, the landscape is

168 initially divided into 'planning units', areas at which management actions are undertaken.

169 Marxan then selects a number of planning units from the total available and calculates whether

170 pre-determined conservation targets (i.e. 30\% of a species' distribution) have been met. Using a

171 simulated annealing optimization algorithm, Marxan then changes some of the selected planning

172 units and calculates whether the change represents an improvement either in terms of

173 conservation targets met or cost. If the newly selected planning units represent an improvement,

174 the process is repeated. If the new planning units do not represent an improvement, the algorithm

175 returns to the previous set of planning units and the process is repeated. Through this iterative

176 process, Marxan can arrive at a set of planning units that achieve all conservation targets at a low

177 cost. Additionally, by implementing Marxan with probability, risks are added as an extra data

178 layer within the analysis, and can be independently minimized, similar to how costs are

179 minimized. By including risks into the Marxan selection process, the risk of failure can be 
included into how Marxan identifies an output reserve network (Tulloch et al., 2013), making the eventual solution more resilient to potential detrimental processes (Hammill et al., 2016). In this study, each Marxan scenario consists of 100 repeat runs, with 1,000,000 iterations being undertaking in each run, where solutions offer $95 \%$ certainty. While recent advances in freshwater systematic conservation planning present methods for implementing multiple zones, multiple actions, and multiple action and threat combinations (Moilanen, Leathwick, \& Quinn, 2011; Cattarino, Hermoso, Carwardine, Kennard, \& Linke, 2015; Hermoso, Cattarino, Kennard, Watts, \& Linke, 2015; Cattarino et al., 2016), these methods do not include protocols for incorporating the risk of conservation actions failing. In the study presented here, understanding and simulating the risk of conservation actions failing was critical to comparing how scenarios that accounted for risk perform compared to scenarios that ignored risk.

\section{$\underline{\text { Study Area }}$}

The MSB was subdivided into tributary sized basins, each of which represented a single planning unit $(\mathrm{n}=519)$ within the Marxan analysis. Tributary basins were derived from hydrologic unit code (HUC 12) basins. The HUC system uses a hierarchical system for assigning catchment sizes. HUC 12 basins capture tributary systems, which can be grouped into larger HUC 8 subbasins, representing medium-sized river basins. The system scales up to HUC 2 regions, outlining large river drainages (EnviroAtlas, 2017). Distributions of Pacific salmon spawning habitat were obtained through the Alaska Department of Natural Resources and spatially correlated with HUC 12 watersheds (Alaska Department of Natural Resources, 2017). The financial costs associated with setting aside a planning unit for conservation were quantified from available land cover data. Land costs associated with urban, agricultural, and undeveloped 
areas were derived from existing parcel costs, as cost per acre, then correlated to corresponding land cover types in the United States Geological Survey Land Cover dataset to determine the spatial distribution of costs (Fig. 2a). Anthropogenic risks to salmon habitat (Fig. 2b) were assessed using an ERS model. ERS models synthesize relevant land uses based on impact intensity, and impact distance to clarify the extent of human caused impacts on the environment (McPherson et al., 2008). This process integrates into Marxan to minimize risks when identifying priority conservation areas (Lessman, Muñoz, \& Bonaccorso, 2014; Evans, Schill, \& Raber, 2015). Risk sources were compiled from urbanized landscape features included residential development, roads, and the threat posed by agriculture. Where applicable, these risks were combined with site-specific risks from mining and oil and gas development (Fig. 2c). Schill and Raber (2008) suggest incorporating risk accumulation in stream networks by applying ERS models to a flow accumulation simulation, as stressors to freshwater ecosystems may originate in distant upstream sources (Fig 1.b) (Lake, 1980; Skelton, Cambray, Lombard, \& Benn, 1995; Moyle \& Randall, 1998; Pringle, Scatena, Paaby-Hansen, \& Nunez-Ferrera, 2000). This process specifies the path that risk flows across the landscape. Esselman and Allan (2011) successfully implemented this modification to address risks to streams in Mesoamerican streams, representing an early application of risk assessment within freshwater systematic conservation planning, offering guidance for this study. Following this procedure, a risk accumulation layer was developed from the ERS model to be input into Marxan with Probability.

\section{$\underline{\text { Marxan with probability Setup }}$}

Protected area connectivity may be customized within the Marxan software. In the most basic form of Marxan, connectivity is customized using a boundary length modifier (BLM), which 
regulates the compactness of the resulting conservation network based on the perimeter of selected priority areas (Ball, Possingham, \& Watts, 2009; Fischer et al., 2010). Adjusting BLM values influences the fragmentation or continuity of the output conservation network, where lower BLM scores produce less connected output networks and vice versa. Despite the customization of these variables, applications of systematic conservation planning across varying ecosystems presents issues. Originally designed for terrestrial and marine conservation, applications of systematic conservation planning to lotic freshwater systems have been plagued by several shortcomings (Abell, Allan, \& Lehner, 2007; Ball et al., 2009). First, calculations of boundary lengths based on an entire study area do not account for hierarchical stream orders within a river basin. By applying existing terrestrial and marine procedures, protected areas may be clustered across catchment boundaries, not defined by stream networks. Several authors have proposed modifications for integrating the linear nature of freshwater connectivity into existing systematic conservation planning software (Hermoso et al., 2011; Esselman \& Allan, 2011; Linke et al., 2012). Of these, Esselman and Allan subdivided natural catchment boundaries into planning units and then calculated neighboring boundary lengths at a larger basin size (2011). By identifying boundaries within subbasins, then reconnecting subbasins within a study area, BLM values identify neighboring planning units within each subbasin for all subbasins across the landscape of interest (Esselman \& Allan, 2011). However, this reconnection of small basins within a larger basin still does not distinguish between upstream and downstream connections. Hermoso et al., (2011) first established the rule for distinguishing connectivity. Next, Linke et al. (2012) improved to the field by clarifying more strict topological rules, utilizing the Pfafstetter stream classification scheme to refine stream network relationships and minimize distances between protected areas. Pfafstetter topological rules for stream networks were compiled from 
the World Wildlife Fund's HydroBASIN database and joined to the study area's HUC 12 catchments (Lehner \& Grill, 2013). The Pfafstetter rules for stream network connectivity were applied to this study for assessing connectivity in defining management priority areas, allowing for the crucial distinction between upstream and downstream connectivity.

\section{$\underline{\text { Scenario Design }}$}

After establishing Marxan inputs and connectivity rules for the analysis, BLM modifiers were tested through a sensitivity analysis to determine the most cost effective and connective matrix of management priorities. Before splitting the analysis into four scenarios the best BLM value for the connectivity rules was determined. At a BLM value of one, the Pfafstetter settings had more connections and a cheaper cost than when no connectivity settings were applied. Therefore, a BLM value of one was held constant for testing all scenarios. For each of the four scenarios, a range of conservation targets were tested for each scenario, ranging from $10 \%$ to $40 \%$ of each species' current distribution, at $10 \%$ increments. Ultimately, a conservation target of $30 \%$ was selected for the final comparison following Betts and Villard (2009), and due to increasingly missed targets above the $30 \%$ threshold. In the Risk ignorant scenario, Marxan was set to ignore anthropogenic risks to salmon spawning habitat and had no aversion to identifying priority conservation areas where oil, gas, and coal deposits were abundant, meaning that conservation decisions were based solely on cost and species distributions. In the Urbanization accounted, all extraction avoided scenario, Marxan was set to account for the anthropogenic risks associated with urbanization identified through the ERS model, while completely avoiding areas rich in oil, gas and coal deposits. Similar to the extraction-avoiding scenario, the Urbanization accounted, coal areas avoided scenario, Marxan was set to account for the anthropogenic risks associated 
272 with urbanization, while completely avoiding areas rich in coal deposits. In the All risks

273 accounted scenario, Marxan was set to account for all anthropogenic risks identified through the

274 ERS, including urbanization and fossil fuel extraction. In this scenario, areas where oil, gas, and

275 coal deposits were abundant were available for inclusion in a conservation network, but the risks

276 to salmon habitat associated with these areas were accounted for in the selection process. Each

277 scenario therefore represents a different attitude towards the different risks present on the

278 landscape, and as a result, threats to the conservation success of each scenario are dependent on

279 how threats manifest.

280

To compare the conservation success and resiliency of each scenario, risk was simulated for each

282 scenario's best solution from Marxan to determine how each scenario would likely perform in

283 the face of conservation threats. Risk was simulated across the landscape-level conservation

284 solutions generated from each of the four scenarios using Monte Carlo numerical simulations

285 (Hammill et al., 2016). Risk was simulated over 1000 iterations, where for each iteration a

286 random number was assigned to each planning unit. If the random number was less than the

287 existing risk assigned to that unit (as defined by the ERS model) the planning unit was deemed

288 'lost' and removed from the scenario's conservation solution. As a result, the removal of

289 planning units subtracts from the total area protected over the landscape, potentially meaning

290 insufficient planning units remain 'not lost' to meet the conservation target. By comparing the

291 ratio of conservation targets met after risk simulation to the cost of implementing the

292 conservation solution, a return on investment was calculated for the landscape solutions

293 generated from each of the four scenarios. 


\section{Results}

Each scenario addressed conservation risks differently, demonstrating the importance of attitude to risk on conservation success. The Risk ignored scenario identified management priorities without accounting for threats from anthropogenic activity or avoiding areas rich in extractive resources (Fig. 3a). In the absence of landscape level risk, the Risk ignored scenario would meet the defined $30 \%$ conservation targets for all five Pacific salmon species, at an estimated cost of $\$ 45,000$ (Fig. 4a). However, when the predicted impact of anthropogenic activities was simulated, the predicted loss of planning units suggests that the solution would only protect 1.67 [SD, 0.08] species (Fig. 4b) due to the number of planning units predicted to be impacted by human encroachment, or extractive resource development. The Risk ignored scenario would therefore yield a return on investment of 0.39 [SD, 0.02] targets met per \$10K spent (Fig. 4c). Under an Urbanization accounted, all extraction avoided scenario (Fig. 3b), where risks associated with urbanization are accounted for in the Marxan analysis but areas with fossil fuels are unavailable for selection, 0 [SD 0.0] targets would be met (Fig. 4a), at an estimated cost of $\$ 98,000$ (Fig. 4b). The Urbanization accounted, all extraction avoided scenario would therefore yield a return on investment of $0[\mathrm{SD}, 0.0]$ targets met per $\$ 10 \mathrm{~K}$ spent (Fig. 4c). Under an Urbanization accounted, coal areas avoided scenario (Fig. 3c), where risks associated with urbanization are accounted for in the Marxan analysis but areas with rich in coal resources are unavailable for selection, 0.97 [SD, 0.02] targets would be met (Fig. 4a), at an estimated cost of $\$ 113,000$ (Fig. 4b). The Urbanization accounted, coal areas avoided scenario would therefore yield a return on investment of 0.085 [SD, 0.002] targets met per $\$ 10 \mathrm{~K}$ spent (Fig. 4c). 
meet an average of 4.73 [SD, 0.05] conservation targets (Fig. 4a) at an estimated cost of $\$ 58,000$ (Fig. 4b). The All risks accounted scenario is therefore predicted to yield the greatest return on investment of 0.81 [SD, 0.009] targets met per \$10K spent (Fig. 4c). Additionally, risk simulations were conducted for each scenario at 10\%, $20 \%$ and $40 \%$ targets. At a $10 \%$ target all scenarios performed best, reaching the greatest return on investments. However, as targets were increased, the ability for each scenario to meet the targets decreased, and costs increased. The All risks accounted scenario was the only scenario able to maintain the number of targets met after risk was simulated onto the solution. However, increases in cost as targets increased, lead to overall decreases in return on investment, even for the All risks accounted scenario (Fig. 5). Once targets reached $40 \%$, both the Coal areas avoided, and All extraction avoided scenarios missed targets for all species and return on investments dropped to 0 .

\section{Discussion}

With increasing anthropogenic stresses being placed on formally pristine habitats, it is critical to investigate how risk of human encroachment should be incorporated into conservation planning (Goudie \& Viles, 2003). Results from this study demonstrate that simply choosing to ignore anthropogenic risk, and base conservation decisions solely on costs and species' distributions represents a poor attitude towards risk as losses incurred prevent conservation targets being met. In addition, simply choosing to avoid locations with containing potentially catastrophic threats means that large portions on the landscape will be excluded, making conservation targets impossible to meet. This was seen as targets increased from $30 \%$ to $40 \%$, the Coal areas avoided and All extraction avoided scenarios, all targets were missed. It is proposed that when making conservation decisions, the best attitude towards risk appears to be a willingness to accept risk 
341 (i.e. do not simply avoid potentially risky areas) but incorporate this risk into conservation

342 decisions (Hammill et al., 2016).

344 Under a Risk ignorant scenario, landscape decisions were based solely on cost and biodiversity

345 data alone. While the solution generated through the Risk ignorant scenario at a target of $30 \%$

346 had the lowest up front cost, the number of conservation targets met following a risk simulation

347 (1.67) was lower than the All risks accounted scenario (4.73) that accommodated for landscape

348 risk. This low number of targets met is due to selected planning units being deemed 'lost' so that

349 insufficient areas remain to meet conservation targets. The low number of targets met mean that

350 a Risk ignorant strategy had a lower overall return on investment $(0.39$ targets met per $\$ 10 \mathrm{~K}$

351 spent) than the All risks accounted scenario (0.81 targets met per $\$ 10 \mathrm{~K}$ spent).

353 Under the Urbanization accounted, all extraction avoided scenario, and the Urbanization

354 accounted, coal areas avoided scenario, large numbers of available planning units were locked

355 out from possible solutions. Simply avoiding areas with fossil fuel development excludes a large

356 portion of the landscape, making it impossible to meet conservation targets. In addition, although

357 the solutions generated under the extraction avoided, and coal areas avoided scenarios did not

358 meet all targets even before risk was simulated, both incurred higher upfront cost than the

359 remaining scenarios. These high costs may be because the exclusion of large areas substantially

360 reduces the options available, forcing the software to include expensive, sub-optimal planning

361 units in the solution in an attempt to meet at least some conservation targets. These high costs

362 also mean that the return on investment predicted to be obtained through the extraction avoided,

363 and coal areas avoided scenarios were the lowest. 
365 Finally, under the All risks accounted scenario landscape decisions incorporated cost,

366 biodiversity data, while minimizing risks. Unlike the scenarios that merely excluded areas with

367 extractive resources present, the All risks accounted scenario accepted risk associated with

368 extractive regions and included that risk into the optimization process. Therefore, the resulting

369 solution maximized return on investment as well as minimizing landscape risk, providing 'risk

370 proofing' for the scenario. Due to the initial 'risk proofing' of the All risks accounted scenario,

371 the Monte Carlo risk simulation affected this scenario less than the other three scenarios. The

372 risk simulation for the All risks accounted scenario removed fewer planning units from desired

373 targets, compared to the other three scenarios. Though the All risks accounted scenario incurred

374 a greater upfront cost than the Risk ignored scenario, the All risks accounted scenario met more

375 targets and yielded the greatest return on investment than the other three scenarios tested.

376 Though the All risks accounted scenario was $29.8 \%$ more costly than the Risk ignorant scenario

377 at the $30 \%$ target, the return on investment for the All risks accounted scenario was twice as

378 large. By including potential anthropogenic risk factors, the All risks accounted scenario

379 identifies priority areas of increased resiliency compared to priority areas identified when risks

380 are ignored. As targets were increased from $10 \%$ to $40 \%$, the All risks accounted scenario was

381 the only scenario able to maintain the number of met targets following simulated risk across the

382 study area. The high number of missed targets under both the Urbanization accounted, all

383 extraction avoided scenario and the Urbanization accounted, coal areas avoided scenario

384 suggests that coordinating effective freshwater salmon conservation in the MSB cannot be

385 achieved by attempting to completely avoid areas rich in extractive resources. Managers may be

386 pre-disposed to adopting risk averse attitudes towards conservation due to fear of failure 
387 (Maguire \& Albright, 2005; Lennox \& Armsworth, 2011; Tulloch et al., 2015). However, results 388 indicated that greater returns are obtained when managers accept certain risks into their salmon conservation strategies, and acknowledge that future energy extraction will influence freshwater

390 salmon conservation.

392 Future efforts to improve the resiliency of salmon conservation in the MSB would be improved through increased data resolution. This study does not clarify how conservation priorities would change from fluctuations to yearly spawning returns. Spawning data provided by Alaska Department of Natural Resources clarified the spatial extent of spawning habitat, but did not clarify the density of redds in spawning areas. Nonetheless, in years with low spawning returns, fish use the same habitat as spawners from greater returning years, but in lower frequency. Therefore, the spatial priorities identified within this study apply for both high and low spawning return years, however the absolute magnitude of spawners is not included. Oceanic conditions have great influence on salmon productivity and mortality; driven by the Pacific Decadal Oscillation (Hare \& Francis, 1995; Beamish et al., 2010). This paper does not suggest that the 402 pelagic life stages of Pacific salmon are less vital for salmon conservation, but instead focused on the novel threats to freshwater salmon habitat from rapidly increasing human activity.

Management Recommendation:

Commercial and sport fishing represent multi-million dollar industries for Alaska, and the MSB is no exception. Fishing industries are bound by the success of seasonal salmon spawning runs and the health of freshwater salmon habitat. Meanwhile, human activities threaten critical 
410 freshwater salmon habitat. By providing economically rooted conservation prioritization, this

411 study intends to provide local managers and conservation groups with useful information to

412 identify conservation opportunities in local river basins conflicted by land uses. The

413 Urbanization risk included scenario suggests that risk adverse management techniques are

414 impractical. The All risks accounted scenario highlights how including anthropogenic risks

415 identify management priorities. The cost increase associated with accounting for All Risk

416 (estimated $\$ 13,000.00$ ) suggests that including risk into management decisions is achievable at a

417 known price. Local non-profit Great Land Trust has been independently developing salmon

418 conservation priorities for the MSB using different prioritization methods. The authors of this

419 paper hope to share their results with both Great Land Trust and other local agencies, to work

420 towards integrating conservation strategies for MSB salmon.

421

\section{Acknowledgements:}

423 We would like to thank the Utah State Ecology Center for facilities and support. We would like

424 to thank Phaedra Budy for her insightful comments during the formulation of the project. Finally,

425 we thank our reviewers for their comments and recommendations.

427 References:

428

429

430

431

432
Abell, R., Allan, J. D., \& Lehner, B. (2007). Unlocking the potential of protected areas for freshwaters. Biological Conservation, 134(1), 48-63. https://doi.org/10.1016/j.biocon.2006.08.017

Alaska Department of Natural Resources. (2017). Alaska spatial datasources. Retrieved from http://www.asgdc.state.ak.us/\#30 
Alderman, S. L., Lin, F., Farrell, A. P., Kennedy, C. J., \& Gillis, T. E. (2016). Effects of diluted bitumen exposure on juvenile sockeye salmon: From cells to performance. Environmental Toxicology and Chemistry, 36(2), 352-360. https://doi.org/10.1002/etc.3533

Ball, I. R., Possingham, H. P., \& Watts, M. (2009). Marxan and relatives: Software for spatial conservation prioritisation. Oxford, United Kingdom: Oxford University Press.

Beamish, R. J., Riddell, B. E., Lange, K. L., Farley Jr., E., Kang, S., Nagasawa, T., ... Urawa, S. (2010). The effects of climate on Pacific salmon - A summary of published literature. $N$. Pac. Anadr. Fish Comm. Spec. Publ. No. 1., 11. Retrieved from http://www.npafc.org/new/publications/Special Publications/LRMP_Synthesis.pdf

Betts, M., \& Villard, M.-A. (2009). Landscape thresholds in species occurrence as quantitative targets in forest management: generality in space and time? Cambridge, United Kingdom: Cambridge University Press. Retrieved from http://www.fsl.orst.edu/flel/pdfs/Betts Villard 2009_Cambridge U Press.pdf

Bode, M., Moilanen, Wilson, Possingham, A., Kerrie, A., \& Possingham, H. (2009). Spatial Conservation Prioritization: Quantitative Methods and Computational Tools. Environmental Conservation; Cambridge, 36(4), 348-349. https://doi.org/10.1017/S037689291000007X

Brittingham, M. C., Maloney, K. O., Farag, A. M., Harper, D. D., \& Bowen, Z. H. (2014). Ecological Risks of Shale Oil and Gas Development to Wildlife, Aquatic Resources and their Habitats. Environmental Science \& Technology, 48(19), 11034-11047. https://doi.org/10.1021/es5020482

Butt, N., Beyer, H. L., Bennett, J. R., Biggs, D., Maggini, R., Mills, M., .. Possingham, H. P. (2013). Biodiversity Risks from Fossil Fuel Extraction. Science, 342(6157), 425-426. https://doi.org/10.1126/science.1237261

Cattarino, L., Hermoso, V., Bradford, L. W., Carwardine, J., Wilson, K. A., Kennard, M. J., \& Linke, S. (2016). Accounting for continuous species' responses to management effort enhances cost-effectiveness of conservation decisions. Biological Conservation, 197(Supplement C), 116-123. https://doi.org/10.1016/j.biocon.2016.02.030

Cattarino, L., Hermoso, V., Carwardine, J., Kennard, M. J., \& Linke, S. (2015). Multi-action planning for threat management: a novel approach for the spatial prioritization of conservation actions. PloS One, 10(5), e0128027. https://doi.org/10.1371/journal.pone.0128027

Cederholm, C. J., Kunze, M. D., Murota, T., \& Sibatani, A. (1999). Pacific Salmon Carcasses: Essential Contributions of Nutrients and Energy for Aquatic and Terrestrial Ecosystems. Fisheries, 24(10), 6-15. https://doi.org/10.1577/1548-8446(1999)024<0006:PSC>2.0.CO;2 
EnviroAtlas. (2017). EnviroAtlas: Hydrologic Unit Codes HUC 4, HUC 8, and HUC 12. Washington D.C. Retrieved from https://enviroatlas.epa.gov/enviroatlas/DataFactSheets/pdf/Supplemental/HUC.pdf

Esselman, P. C., \& Allan, J. D. (2011). Application of species distribution models and conservation planning software to the design of a reserve network for the riverine fishes of northeastern Mesoamerica. Freshwater Biology, 56(1), 71-88. https://doi.org/10.1111/j.1365-2427.2010.02417.x

Evans, J. S., Schill, S., \& Raber, G. (2015). A Systematic Framework for Spatial Conservation Planning and Ecological Priority Design: An Example from St. Lucia, Eastern Caribbean. Central American Biodiversity, 603-623. https://doi.org/10.1007/978-1-4939-2208-6_26

Fausch, K. D., Torgersen, C. E., Baxter, C. V, \& Li, H. W. (2002). Landscapes to Riverscapes: Bridging the Gap between Research and Conservation of Stream Fishes: A Continuous View of the River is Needed to Understand How Processes Interacting among Scales Set the Context for Stream Fishes and Their Habitat. BioScience, 52(6), 483-498. https://doi.org/10.1641/0006-3568(2002)052[0483:LTRBTG]2.0.CO;2

Fischer, D. T., Alidina, H. M., Steinback, C., Lombana, A. V, de Arellano, P. I., Ferdana, Z., \& Klein, C. J. (2010). Ensuring Robust Analysis-Marxan good practices handbook version 2. Retrieved from http://planet.uwc.ac.za/nisl/BDC332/Text_Book_Marxan_Good_Handbook/Marxan_chp8_ 9.pdf

Gende, S. M., Edwards, R. T., Willson, M. F., \& Wipfli, M. S. (2002). Pacific Salmon in Aquatic and Terrestrial EcosystemsPacific salmon subsidize freshwater and terrestrial ecosystems through several pathways, which generates unique management and conservation issues but also provides valuable research opportunities. BioScience, 52(10), 917-928. https://doi.org/10.1641/0006-3568(2002)052[0917:PSIAAT]2.0.CO;2

Goudie, A. S., \& Viles, H. A. (2003). The Earth Transformed: An Introduction to Human Impacts on the Environment. Malden, Massachusetts: Blackwell Publishers Ltd.

Hammill, E., Tulloch, A. I. T., Possingham, H. P., Strange, N., \& Wilson, K. A. (2016). Factoring attitudes towards armed conflict risk into selection of protected areas for conservation. Nature Communications, 7. https://doi.org/10.1038/ncomms11042

Hare, S. R., \& Francis, R. C. (1995). Climate change and salmon production in the Northeast Pacific Ocean. Can. Spec. Publ. Fish. Aquat. Sci., 121, 357-372.

Hermoso, V., Linke, S., Prenda, J., \& Possingham, H. P. (2011). Addressing longitudinal connectivity in freshwater systematic conservation planning. Freshwater Biology, 56(1), 57-70. https://doi.org/10.1111/j.1365-2427.2009.02390.x 
Hermoso, V., Cattarino, L., Kennard, M. J., Watts, M., \& Linke, S. (2015). Catchment zoning for freshwater conservation: refining plans to enhance action on the ground. Journal of Applied Ecology, 52(4), 940-949. https://doi.org/10.1111/1365-2664.12454

Hollander, Z. (2014, October). State grants permit to Usibelli in disputed Wishbone Hill mine project. Alaska Dispatch News. Retrieved from https://www.adn.com/energy/article/usibelli-gets-disputed-wishbone-hill-minepermit/2014/10/15/

Hughes, D. W. (2013). A Comprehensive Inventory of Impaired Anadromous Fish Habitats in the Matanuska Susitna Basin, with Recommendations for Restoration, 2013. Retrieved from http://www.adfg.alaska.gov/static/regulations/regprocess/fisheriesboard/pdfs/20132014/uci/anadromous_fish.pdf

Juday, C., Rich, W. H., Kemmerer, G. I., \& Mann, A. (1932). Limnological studies of Karluck Lake, Alaska 1926-1930. Bulletin of the Bureau of Fisheries, 47, 407-434.

Keith, B., Erben, S., \& Dapcevich, S. (2010). Alaska Economic Trends April 2010. Retrieved from http://labor.state.ak.us/trends/apr10.pdf

Lake, P. S. (1980). Conservation. In An Ecological Basis for Water Resource Management (pp. 163-173). Canberra, Australia: Australian National University Press.

Lehner, B., \& Grill, G. (2013). Global river hydropgrahy and network routing: baseline data and new approaches to study the world's large river systems. Hydrological Processes, 27(15), 2171-2186. https://doi.org/10.1002/hyp.9740

Lennox, G. D., \& Armsworth, P. R. (2011). Suitability of short or long conservation contracts under ecological and socio-economic uncertainty. Ecological Modelling, 222(15), 28562866. https://doi.org/10.1016/j.ecolmodel.2011.04.033

Lessmann, J., Muñoz, J., \& Bonaccorso, E. (2014). Maximizing species conservation in continental Ecuador: a case of systematic conservation planning for biodiverse regions. Ecology and Evolution, 4(12), 2410-2422. https://doi.org/10.1002/ece3.1102

Linke, S., Kennard, M. J., Hermoso, V., Olden, J. D., Stein, J., \& Pusey, B. J. (2012). Merging connectivity rules and large-scale condition assessment improves conservation adequacy in river systems. Journal of Applied Ecology, 49(5), 1036-1045. https://doi.org/10.1111/j.1365-2664.2012.02177.x

Linke, S., Pressey, R. L., Bailey, R. C., \& Norris, R. H. (2007). Management options for river conservation planning: condition and conservation re-visited. Freshwater Biology, 52(5), 918-938. https://doi.org/10.1111/j.1365-2427.2006.01690.x 
Maguire, L. A., \& Albright, E. A. (2005). Can behavioral decision theory explain risk-averse fire management decisions? Forest Ecology and Management, 211(1), 47-58. https://doi.org/10.1016/j.foreco.2005.01.027

Mat-Su Salmon Partnership. (2013). Conserving Salmon Habitat in the Mat-Su Basin: The Stragetic Action Plan of the Mat-Su Basin Salmon Habitat Partnership 2013 Update. Retrieved from http://www.matsusalmon.org/dev/wp-content/uploads/2012/10/MatSuSalmon-Strategic-Action-Plan-2013_revOct15.pdf

McPherson, M., Schill, S., Raber, G., John, K., Zenny, N., Thurlow, K., \& Sutton, A. H. (2008). GIS-based Modeling of Environmental Risk Surfaces (ERS) for Conservation Planning in Jamaica. Journal of Conservation Planning, 4, 60-89.

Metiva, M., \& Hanson, D. (2008). Mat-Su Comprehensive Economic Development Strategy: December 2008 Update. Retrieved from https://www.matsugov.us/docman/doc_view/842

Moilanen, A., Wilson, K. A., \& Possingham, H. P. (2009). Spatial Conservation Prioritization: Quantitative Methods and Computational Tools. Oxford, United Kingdom: Oxford University Press. Retrieved from http://library.wur.nl/WebQuery/clc/1909723

Moilanen, A., Leathwick, J. R., \& Quinn, J. M. (2011). Spatial prioritization of conservation management. Conservation Letters, 4(5), 383-393. https://doi.org/10.1111/j.1755263X.2011.00190.x

Moyle, P. B., \& Randall, P. J. (1998). Evaluating the biotic integrity of watersheds in the Sierra Nevada, California. Conservation Biology, 12(6), 1318-1326. https://doi.org/10.1111/j.1523-1739.1998.97161.x

Municipality of Anchorage. (2001). Anchorage Bowl Comprehensive Plan: 2020. Anchorage, AK. Retrieved from https://www.muni.org/Departments/OCPD/Planning/Documents/f2020_chapt_2.pdf

Naidoo, R., Balmford, A., Ferraro, P. J., Polasky, S., Ricketts, T. H., \& Rouget, M. (2006). Integrating economic costs into conservation planning. Trends in Ecology \& Evolution, 21(12), 681-687. https://doi.org/10.1016/j.tree.2006.10.003

Possingham, H. P., Wilson, K. A., Andelman, S. J., \& Vynne, C. H. (2006). Protected areas: goals, limitations, and design. In M. J. Groom, G. K. Meffe, \& C. R. Carroll (Eds.), Principles of Conseration Biology (3rd ed., pp. 509-533). Sunderland, MA: Sinauer Associates, Inc.

Pringle, C. M., Scatena, F. N., Paaby-Hansen, P., \& Nunez-Ferrera, M. (2000). River conservation in Latin America and the Caribbean. In P. J. Boon, B. R. Davies, \& G. E. Petts (Eds.), Global Perspectives on River Conservation: Science, Policy, and Practice (pp. 4177). New York: John Wiley and Sons Ltd. 
Reimchen, T. E. (2000). Some ecological and evolutionary aspects of bear-salmon interactions in coastal British Columbia. Canadian Journal of Zoology, 78(3), 448-457. https://doi.org/10.1139/z99-232

Schill, S., \& Raber, G. (2008). Protected Area Tools (PAT) for ArcGIS software https://gispatools.org. Arlington, Virginia.

Shields, P., \& Dupuis, A. (2012). Upper Cook Inlet Commercial Fisheries Annual Management Report, 2011.

Shuman, R. F. (1950). Bear Depredations on Red Salmon Spawning Populations in the Karluk River System, 1947. The Journal of Wildlife Management, 14(1), 1-9. https://doi.org/10.2307/3795972

Skelton, P. H., Cambray, J. A., Lombard, A., \& Benn, G. A. (1995). Patterns of distribution and conservation status of freshwater fishes in South Africa. South African Journal of Zoology, 30(3), 71-81. https://doi.org/10.1080/02541858.1995.11448375

Stromberg, J. A., \& Scholz, N. L. (2011). Estimating the future decline of wild coho salmon populations resulting from early spawner die-offs in urbanizing watersheds of the Pacific Northwest, USA. Integrated Environmental Assessment and Management, 7(4), 648-656. https://doi.org/10.1002/ieam.219

Sweet, D., Ivey, S., \& Rutz, D. (2003). Area management Report for the Recreational Fisheries of Northern Cook Inlet, 2001 and 2002. Retrieved from http://www.sf.adfg.satate.ak.us/FedAidPDFs/fmr03-10.pdf

Tulloch, A. I. T., Maloney, R. F., Joseph, L. N., Bennett, J. R., Di Fonzo, M. M. I., Probert, W. J. M., ... Possingham, H. P. (2015). Effect of risk aversion on prioritizing conservation projects. Conservation Biology, 29(2), 513-524. https://doi.org/10.1111/cobi.12386

Tulloch, V. J., Possingham, H. P., Jupiter, S. D., Roelfsema, C., Tulloch, A. I. T., \& Klein, C. J. (2013). Incorporating uncertainty associated with habitat data in marine reserve design. Biological Conservation, 162, 41-51. https://doi.org/10.1016/j.biocon.2013.03.003

Willson, M. F., Gende, S. M., \& Marston, B. H. (1998). Fishes and the Forest: Expanding perspectives on fish-wildlife interactions. BioScience, 48(6), 455-462. https://doi.org/10.2307/1313243 


\section{$600 \quad$ Figure legends}

601 Fig. 1. Flow chart of the methods implemented in this study. Four distinct scenarios were tested,

602

603

604

605

606

607

608

609

610

611

612

613

614

615

616

617

618

619

620

621

622
1) Risk ignored; 2) Urbanization accounted, all extraction avoided; 3) Urbanization

accounted, coal areas avoided; 4) All risks accounted.

Fig 2. Spatial distributions of data incorporated into Marxan analysis. (a) Land costs based on available land cover data, land costs are calculated per hectare in US dollars. (b)

Distribution of environmental risks derived from ERS model. Inset describes how risk accumulation flows through stream network. (c) Fossil fuel resources within the MatanuskaSusitna Basin.

Fig 3. Planning units selected for the best solution under each Marxan scenario (a) Risk ignored scenario, (b) Urbanization accounted, all extraction avoided, (c), Urbanization accounted, coal areas avoided, (d) All risks accounted.

Fig. 4. Results summary for the four different risk scenarios following simulation of the impacts of environmental risk, (a) Number of conservation targets met, (b) Cost of best solution, (c) Return on investment.

Fig. 5. Results summary for the four different risk scenarios following simulation of the impacts of environmental risk tested at targets from $10 \%$ to $40 \%$, (a) Number of conservation targets met, (b) Cost of best solution, (c) Return on investment. 


\section{Figure 1}

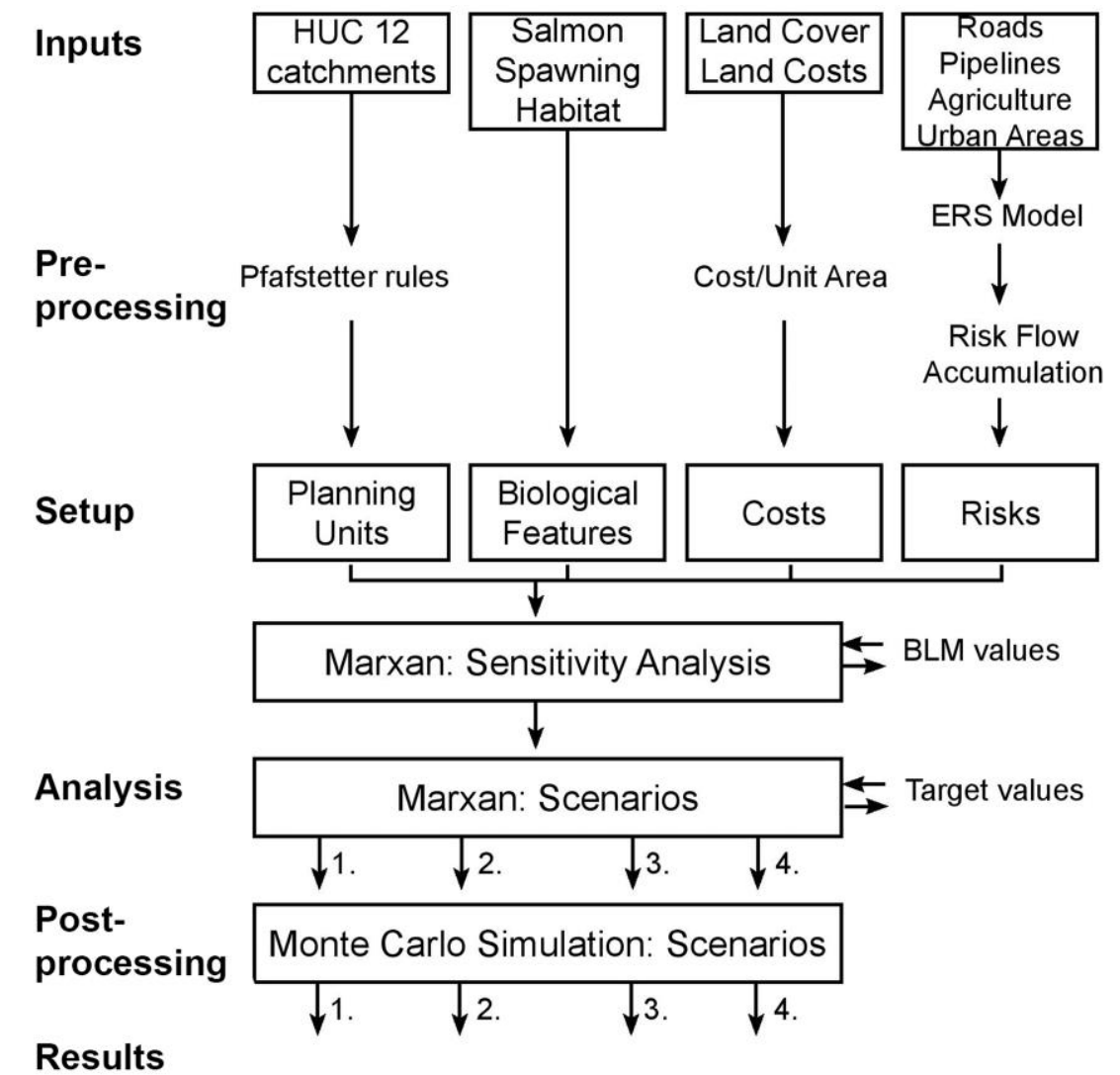

624

625 

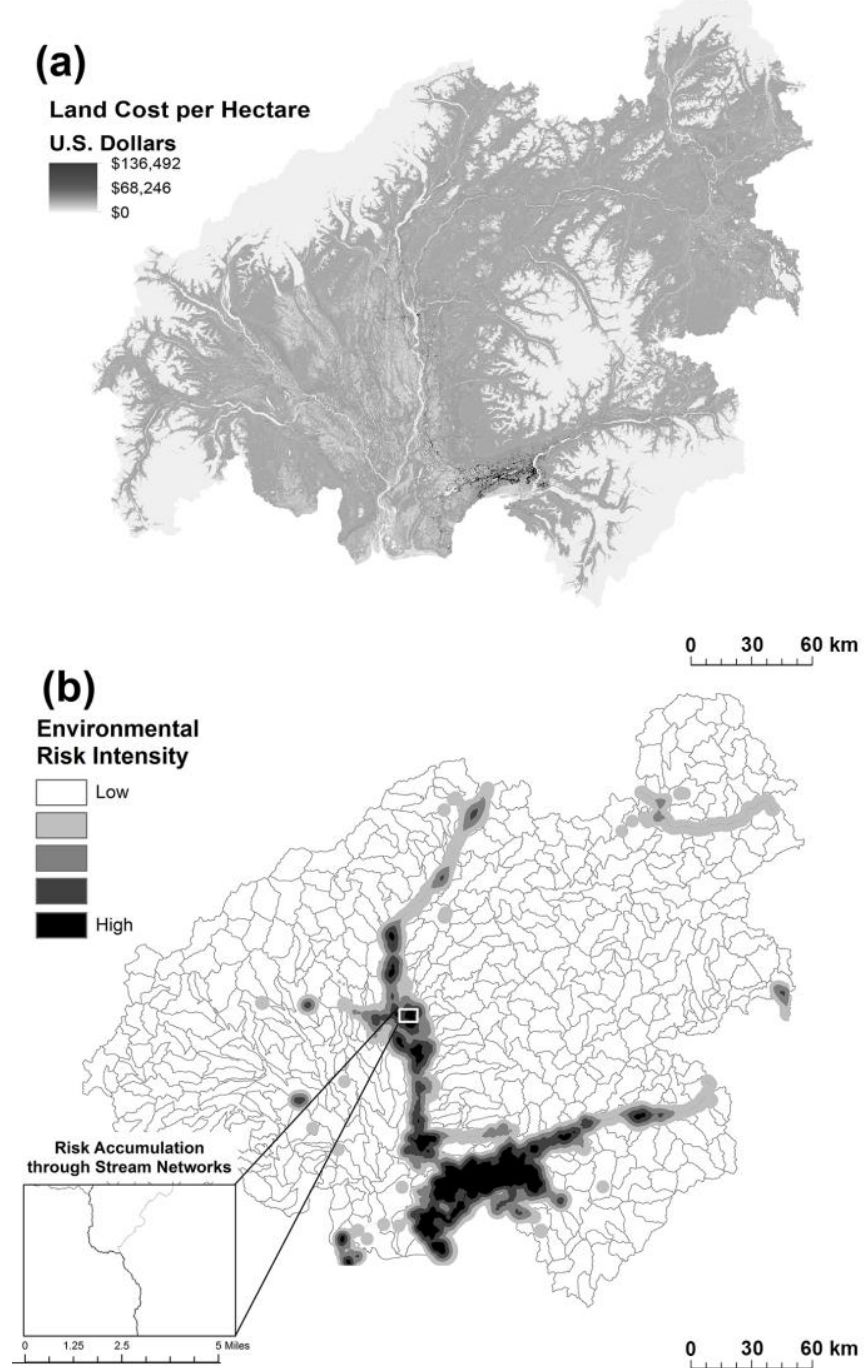

(c)

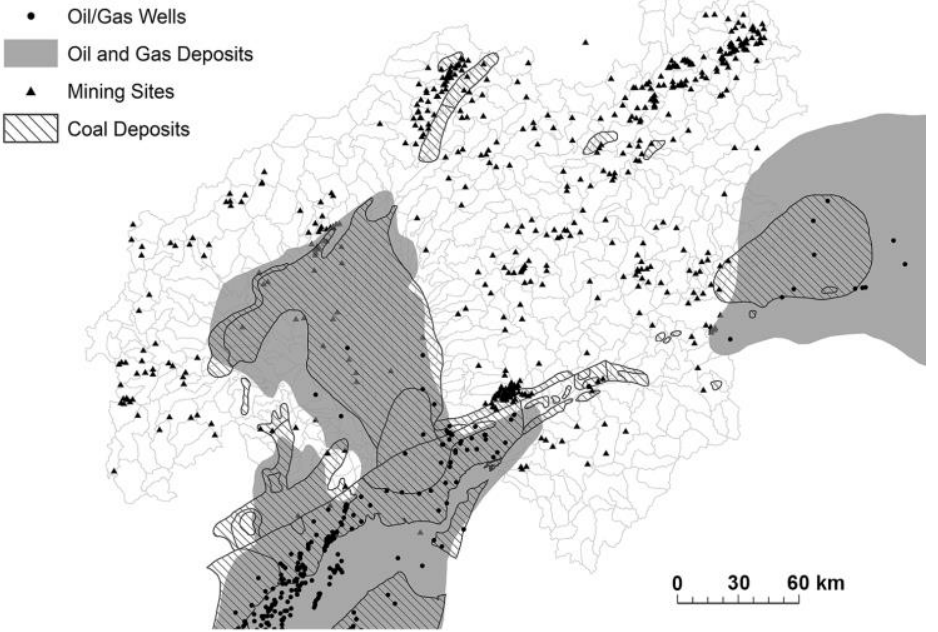


(a)

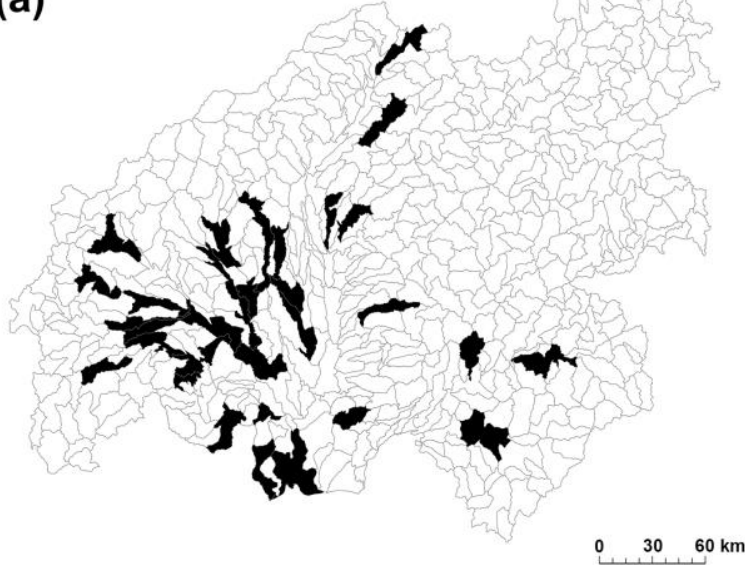

(c)

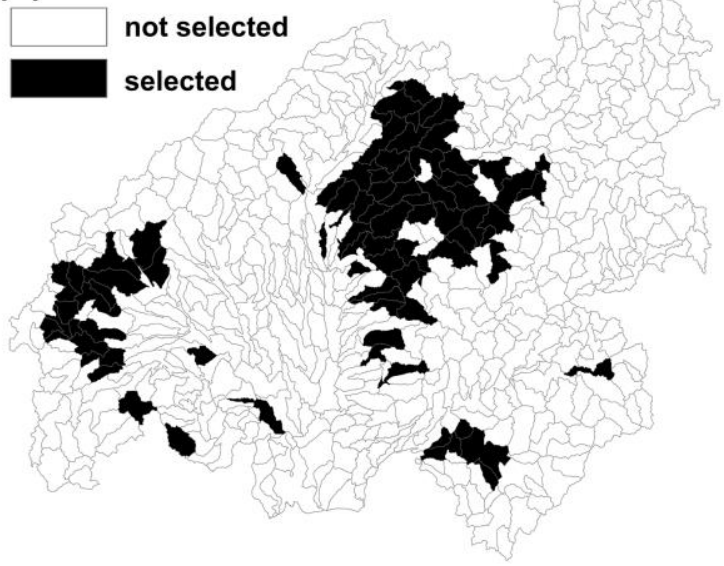

(b)

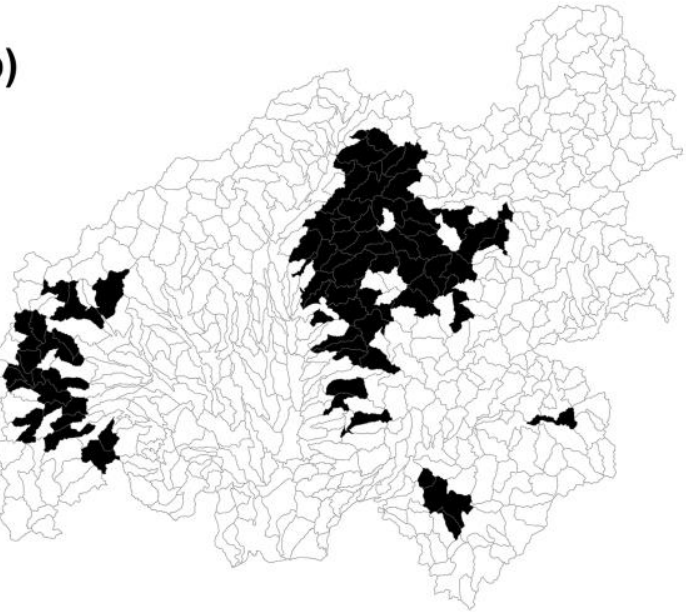

(d)

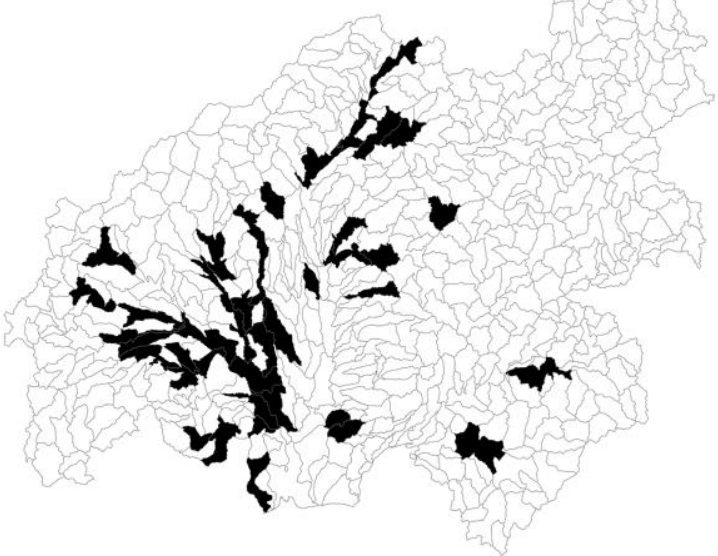




\section{Figure 4}

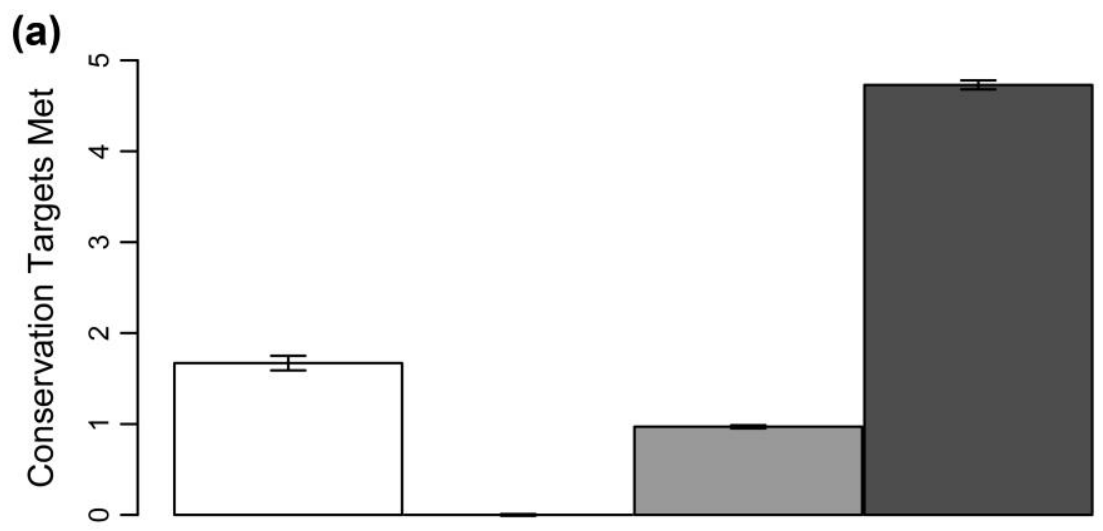

(b)

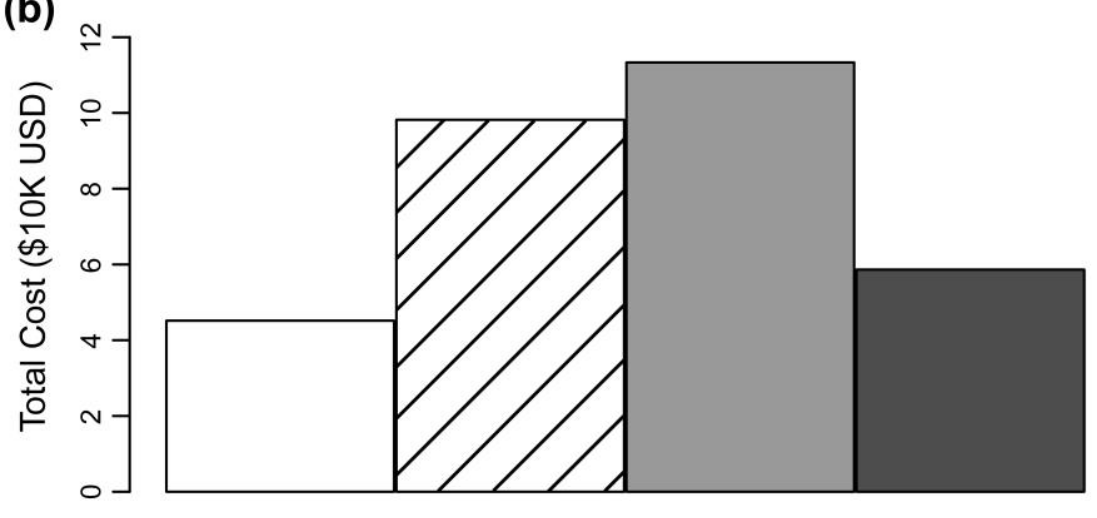

(c)

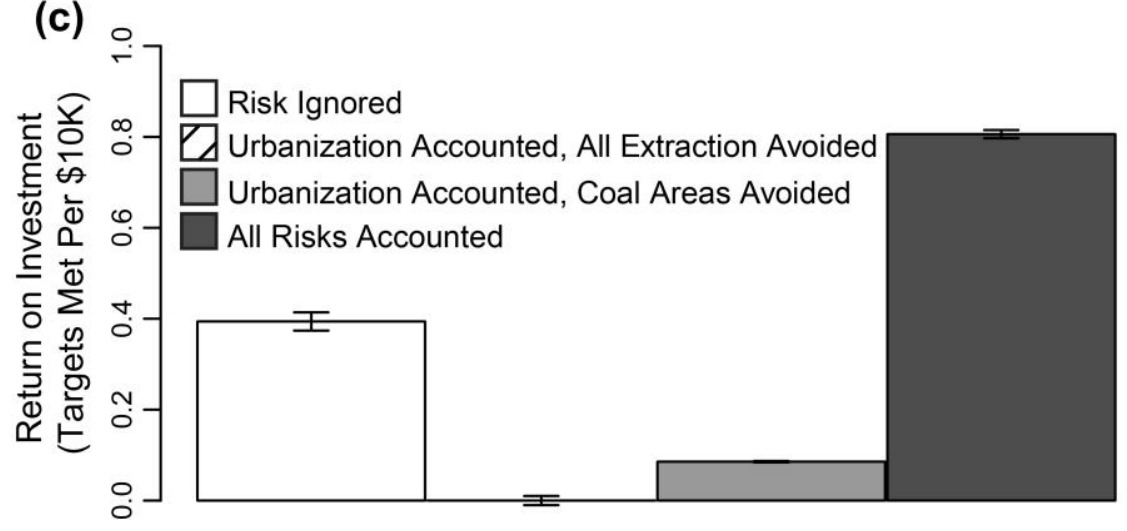


(a)
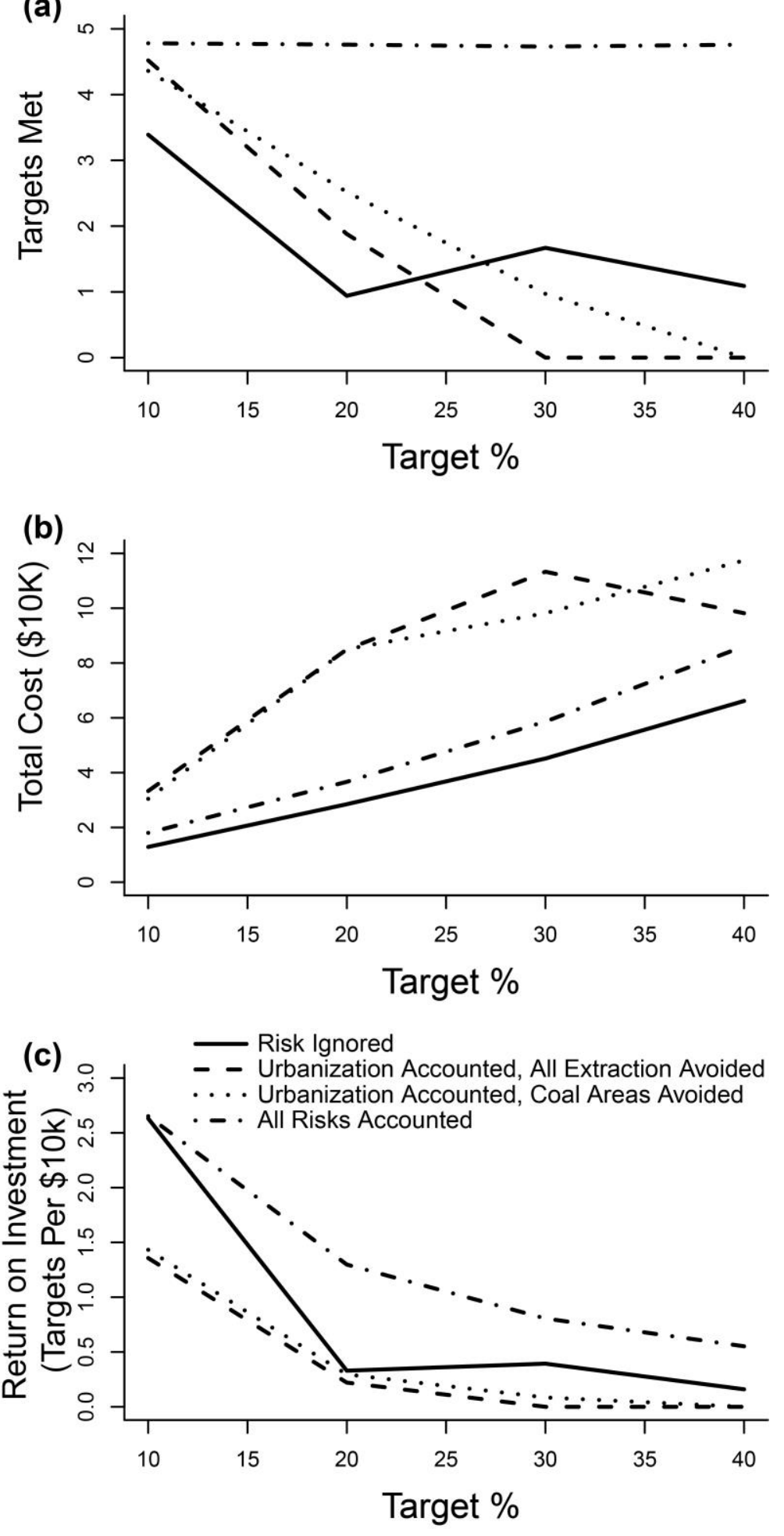